\title{
PARADIGMAS Y ENFOQUES TEÓRICOS EN LA SOCIOLOGÍA DE LA MÚSICA
}

\author{
PARADIGMS AND THEORETICAL APPROACHES IN SOCIOLOGY \\ OF MUSIC
}

\author{
JAVIER NoYA Javiernoya@yahoo.com \\ Universidad Complutense de Madrid. España. \\ FERnÁn DEL VAL fernandelval@gmail.com \\ Universidad Nacional de Educación a Distancia (UNED). España. \\ Dafne Muntanyola dafne.muntanyola@uab.cat \\ Universitat Autònoma de Barcelona. España.
}

\section{RESUMEN}

El objetivo de este artículo es plantear un estado de la cuestión sobre las corrientes teóricas en la sociología de la música actual. A escala internacional, la sociología de la música ha sido un campo pródigo en teorías más que en investigación empírica, sobre todo en la tradición europea. El escenario teórico que encontramos en la sociología de la música sigue el pluralismo paradigmático de la sociología general. Esto se refleja en una variedad de enfoques, que presentaremos aquí, y que diferenciamos según el plano en el que operan: macro, meso y micro. Ofrecemos una síntesis de las propuestas de clásicos como Weber, Adorno, DeNora y Bourdieu, e incluimos nuevas propuestas metodológicas desde el análisis de redes sociales, la etnografía y los estudios culturales. Para consolidar un marco teórico de referencia debemos huir de la trampa postmoderna, que renuncia a la crítica sociológica, y reconoceremos el carácter necesario de una verdadera teoría social.

\section{Palabras Clave}

Adorno; Micro-macro; Pluralismo; Sociología de la música; Teoría sociológica.

\section{ABSTRACT}

The aim of this paper is to present the state of affairs on the theoretical currents in the sociology of contemporary music. Internationally, the sociology of music has been productive in empirical research, especially in the European tradition. The theoretical scenario found in the sociology of music is based on a pluralistic paradigm which follows general trends in sociology. This shows in a variety of approaches, which we will present here, which differ according to the plane in which they operate: macro, meso and micro. We provide a summary of classic proposals like Weber, Adorno, Bourdieu and DeNora, and include new methodological proposals from social network analysis, ethnography and cultural studies. We consider that in order to consolidate a theoretical framework we must avoid the postmodern trap, which avoids sociological criticism, and recognize the need for doing true social theory.

\section{KEYWORDS}

Adorno; Micro-Macro; Pluralism; Sociology of Music; Sociological Theory. 


\section{INTRODUCCIÓN}

El objetivo de este texto es tan modesto como necesario: plantear un estado de la cuestión y un balance de las corrientes teóricas en la sociología de la música en la actualidad. Este tipo de trabajo no abunda en España ni en el campo académico internacional. Además, la sociología de la música ha sido un campo pródigo en teorías más que en investigación empírica, sobre todo en la tradición europea. Esto se refleja en una gran variedad de enfoques, que presentaremos aquí. En realidad, el escenario teórico que encontramos en la sociología de la música no se aparta demasiado del de la sociología en general: pluralismo paradigmático 0 , en términos teóricos, la anomia denunciada por Pierre Bourdieu. Por ello, en el trabajo realizamos una selección de un campo muy rico. Partimos de la distinción entre teoría sociológica, entendida como análisis positivo de la realidad social, de "el ser", y teoría social o pensamiento crítico, cuestionando la realidad desde valores o principios normativos, el "deber ser". Se trata de un método de exposición, no de investigación. Hay teóricos que se han centrado más en los mecanismos o leyes, evitando la crítica; otros han prestado más atención a la crítica evitando el análisis. Pocos han conjugado ambas - pero esto también sucede fuera de este campo, como demuestra la gran excepción del marxismo analítico.

Dentro de los análisis positivos diferenciamos los enfoques según el plano en el que operan, como vemos en la Tabla 1.

Tabla 1.

Planos y dimensiones de la música como proceso social y artístico.

\begin{tabular}{|c|c|c|c|c|}
\hline \multirow[t]{2}{*}{ Plano de análisis } & \multirow[t]{2}{*}{ Género musical } & \multicolumn{3}{|c|}{ Dimensiones del proceso musical } \\
\hline & & $\begin{array}{l}\text { Creación/ } \\
\text { Interpretación }\end{array}$ & $\begin{array}{l}\text { Intermediación/ } \\
\text { Industria cultural }\end{array}$ & $\begin{array}{c}\text { Recepción/ } \\
\text { Consumo }\end{array}$ \\
\hline Macro & $\begin{array}{l}\text { Clásica } \\
\text { Jazz } \\
\text { Rock }\end{array}$ & & & \\
\hline Meso & $\begin{array}{l}\text { Clásica } \\
\text { Jazz } \\
\text { Rock }\end{array}$ & & & \\
\hline Micro & $\begin{array}{l}\text { Clásica } \\
\text { Jazz } \\
\text { Rock }\end{array}$ & & & \\
\hline
\end{tabular}


- Macro: con el análisis de grandes estructuras, procesos e instituciones sociales.

- Micro: el estudio de la interacción cara a cara.

- Meso: basado en el análisis relacional de redes y el concepto de capital social.

Los autores que agrupamos en cada plano abordan además distintos aspectos del proceso musical: unos se centran en la dimensión creativa o de producción, otros en el momento de intermediación de las industrias culturales y, finalmente, otros se basan en la recepción o en los procesos de consumo cultural. No están todos los que son -era imposible- pero sí que son todos los que están. El texto no es un simple balance, también hay crítica, como a Adorno y al postmodernismo. Para cada uno de los enfoques más importantes ilustramos los argumentos del autor o escuela con ejemplos. Pueden ser del rock, el jazz o la música clásica, indistintamente. En un último apartado sintetizamos los enfoques y exponemos tareas futuras para la sociología de la música.

\section{EL SILENCIO PARAdÓJICO DE LA SOCIOLOGÍA DE LA MÚSICA}

Hay que comenzar subrayando la excepcionalidad de la música en la sociología de la cultura. Comparada con las artes plásticas o la literatura, la música ha recibido menos atención por parte de los sociólogos, quizás por su carácter más abstracto y esotérico, en especial si pensamos en la música culta; pero la popular tampoco ha tenido lugar en la musicología hasta hace poco. Como pone de relieve Pierre Bourdieu en su análisis del campo literario francés del XIX en Las reglas del arte, desde el campo del arte, las opciones, estilos y tendencias artísticas se presentan como naturales y no como arbitrarias, en el sentido de culturales. Por ejemplo, la distinción entre música culta y música popular se presenta como una división necesaria, que va de soi, y no como el producto de prácticas y juicios sociales a lo largo del tiempo. Esta negación de las "reglas del juego" del arte como actividad social contribuye a la dimensión ritual, religiosa y, como hemos dicho, mística o esotérica de la actitud artística y de sus prácticas de producción, difusión y consumo.

La consecuencia de la mistificación de la cultura es la lejanía entre la música y la sociología. Por un lado, se produce un fenómeno de elitismo en la música clásica, con un carácter hermético para unos sociólogos que, solo en el caso de Alemania, provenían de una burguesía cultivada en armonía, formas musicales, etc. (por ejemplo, Simmel y Weber, como veremos más adelante). Tampoco favoreció la aproximación de los sociólogos al fenómeno musical desde una perspectiva empírica. Por otro lado, el mito romántico del artista como genio individual ha alejado a los músicos de la sociología que, según la percepción popular, busca regularidades y define factores sociales. El problema ha ganado complejidad con la llegada de la música popular de masas, más 
accesible también a los sociólogos, y que pone de manifiesto la construcción social de la figura artística. Por la mercantilización de la que ha sido víctima la música popular en sus orígenes, se tiende a pensar que está más sujeta a las condiciones sociales que la música culta, pero como venimos diciendo, la "música absoluta" no existe. Ahora bien, tampoco existe una sociología absoluta que cuestione la música absoluta pero no a sí misma. El mejor ejemplo de este peligro de reificación es la obra de Theodor Adorno y sus sesgos a la hora de analizar el jazz, como veremos en otra sección. Es uno de los mayores puntos ciegos de la teoría crítica, y forma parte de los errores de valoración de la sociología de la música.

El "no-lugar" de la música en la sociología contrasta con la atención que le ha prestado la antropología. La rica producción teórica y empírica de la antropología y la etnología contrasta con la escasez de literatura sociológica. No existe en la sociología clásica un equivalente a autores como Alan Lomax o Carlos Reynoso. Los autores que presentamos aquí, como Weber, Simmel o Adorno, constituyen una gran excepción -tanto por sus éxitos como por sus fracasos-y no la regla de la producción sociológica.

Este "paradójico silencio" resulta todavía más sorprendente en el contexto actual, dado el nuevo auge que ha cobrado la sociología cultural con el giro postmoderno. Pero quizás este ha sido el origen del silencio: el iconocentrismo. La tendencia del iconocentrismo también abarcó otras disciplinas artísticas, como la fotografía o el cine, sobre todo entre los miembros de la Escuela de Frankfurt —algunos de forma más matizada, como Benjamin (1936); otros de manera más descarnada, como Adorno-y pensadores culturales como McLuhan (1967) y Sontag (1973). La fotografía como disciplina artística nació con una clara voluntad documental, para diferenciarse de la pintura, por lo que el pensamiento social asoció la fotografía con realismo y veracidad. Solo recientemente la historiografía de la fotografía ha reconocido que ya desde los inicios existía también en los primeros fotógrafos vocación de inventar, de crear mundos de fantasía y de ficción, al igual que en el doble nacimiento del cine con Lumière y Meliès. En el caso de la fotografía, las fotografías de Daguerre de bodegones y calles vacías convivían con las fotos de fantasmas y hadas de la época victoriana (Fontcuberta 2003). De manera más reciente, los mismos estudios culturales (Williams 1982; Eagleton 2000) han puesto de manifiesto que la literatura, el cine y la fotografía no pueden entenderse como productos culturales homogéneos, sino que son parte de una pluralidad de prácticas y de valores ligados a un contexto social específico. Por ejemplo, pensemos en el estudio de Paul Willis (1977) sobre subculturas juveniles, o el de Terry Eagleton (2000) sobre la definición del concepto de cultura.

Sin embargo, los postmodernos han privilegiado lo visual sobre lo auditivo. No podemos dejar de señalar el empuje de la economía de la cultura o de la música. Mientras la sociología postmoderna se perdía en cuestiones filosófico-ontológicas, la economía empezaba a incorporar variables sociales a sus análisis explicativos. El ejemplo más evidente es el de la teoría del capital social. En el Journal of Cultural Economics se encuentran mejores artículos de sociología de la música que en el postmoderno Popular Music and Society. Tendremos ocasión de referimos a alguno de ellos. 
Otro de los rasgos característicos de la reciente sociología de la música ha sido el mayor énfasis puesto en el consumo. Aquí no tenemos espacio para abordarlo, pero la piratería musical y los cambios en las formas de consumo están abriendo un nuevo y prolífico campo de investigación. Probablemente los hábitos de escucha sean más fáciles de "enclasar", de explicar por la clase social, que las pautas de creación, por definición más libres. 0 , más que libres, las competencias de los artistas profesionales traducen hábitos naturalizados que promueven la desconexión, no solo del ciudadano de a pie, sino de críticos e investigadores, entre el criterio del gusto musical y su raíz social en los procesos de socialización. Es la existencia de este enlace el que llevó a Bourdieu a elaborar la sociología de la creación literaria que ya hemos mencionado (1994), mientras que solo prestó atención -y no mucha- al consumo musical.

Los trabajos sobre la "distinción musical" de Bourdieu, o la crítica desde el "omnívoro cultural" de Peterson (1996), son más ricos e interesantes que los de los mismos autores sobre el consumo y la recepción. El análisis de la creación está en pañales: empieza a desarrollarse, aunque con limitaciones. Como veremos, el enfoque de la producción de Peterson (1997) en realidad es más una sociología de la mediación, de la industria cultural, antes que una sociología de la creación.

\section{LOS ENFOQUES MACROSOCIOLÓGICOS EN SOCIOLOGÍA DE LA MÚSICA}

El ominoso silencio de la sociología es todavía más llamativo si pensamos que la música sí estuvo en los orígenes de esta disciplina. Un factor importante fue la cultura burguesa de buena parte de los sociólogos alemanes de finales del siglo XIX y principios del XX. Max Weber es sin duda el mejor exponente de esta tradición de la sociología alemana. Como relata Marianne, su viuda, era un gran melómano. En una de las últimas ediciones que publicó (en vida) de la Ética protestante cita varias veces las óperas de Wagner. Todo apunta a que Weber planeaba escribir una sociología de la música, de la que solo pudo llevar a cabo el artículo "Fundamentos racionales y sociológicos de la música" hace 100 años, puesto que lo escribió en 1910-11, aunque no fuese publicado hasta 1921. En el célebre ensayo que pasó a engrosar la monumental obra póstuma Economía y Sociedad tomó la armonía occidental como ilustración del proceso de racionalización occidental. También destaca el análisis del piano como instrumento que reflejaba a la perfección el cambio social operado en la música.

La originalidad en el planteamiento de Weber estaba en la búsqueda de los fundamentos sociales y racionales de lo que en principio es individual e irracional: el arte y la música. Fijémonos en que la estrategia es parecida a la de Durkheim en El Suicidio, por encima de las grandes diferencias teóricas y metodológicas que separaban a los dos clásicos. El proceso de "estandarización" y homogeneización discurre en paralelo en los instrumentos y en la notación musical. Weber destaca el papel central de la Iglesia en la homogeneización del canon musical. Fue la fuerza centrípeta de la música vocal 
eclesiástica, la polifonía medieval. La complejidad del contrapunto obligó a una racionalización. La transformación clave fue la ordenación racional del espacio sonoro y el surgimiento del temperamento, la "digitalización", diríamos hoy día: el paso de lo analógico a lo digital. El proceso no fue lineal y estuvo salpicado de debates y conflictos. El mismo Bach se opuso y propuso su propio sistema. Poco a poco, sin embargo, la música instrumental también se emancipó de la vocal. El proceso se consuma en el Barroco. La estandarización era más compleja, si cabe, que en el caso de la música vocal por la explosión de la diversidad de la música de las cortes: el momento centrífugo. Weber destaca el papel clave que desempeñaron los gremios de artesanos y lutieres en cuanto a la "estandarización" de los instrumentos, dada la necesidad de ahorrar tiempo y dinero en la producción artesanal de los mismos, pero también para facilitar los procesos de aprendizaje de los artesanos. Todo esto llevó a desarrollar instrumentos con la misma afinación y timbre.

Posteriormente, ya a finales del XIX y principios del XX, comenzará la producción en serie de instrumentos. Se darán también cambios hacia la "estandarización" con origen en la internacionalización de la música clásica. El clavecín o el piano tradicional, con su mecanismo de madera, sufría en los climas más cálidos y húmedos, como en los del sur o tropicales. De ahí surge la necesidad de sustituir la madera por el metal, y el primer fabricante será el norteamericano Steinway. Por lo tanto, la internacionalización y la racionalización fueron procesos paralelos, ayudados por la producción en masa de la industria, que permitió una estandarización aún mayor. Reparemos en que ya hay entonces en Weber un tratamiento de la tecnología como variable, pero en el que es la variable dependiente y no la independiente, como sucederá más tarde en la teoría postmoderna del "actor red" de Bruno Latour (2005). La tecnología musical es una variable del proceso de racionalización de la modernidad, proceso complejo que engloba más dimensiones sociales de cambio, como la estandarización burocrática, la individualización y la consolidación del tejido urbano de la ciudad.

Dentro de los enfoques macro, otro de los "clásicos" que analizó la música, aunque este más contemporáneo, fue Theodor Adorno (1962; 2000; 2009), sin olvidar que se trataba de un compositor de la vanguardia vienesa, y que por lo tanto "era juez y parte". Esta condición se pone de inmediato de manifiesto cuando Adorno analiza la música popular, que despreciaba profundamente. Hizo gala de un elitismo que lo invalidaría como analista. Como es bien sabido, el argumento central de Adorno en su análisis de todos los géneros musicales giraba en torno a los efectos de la mercantilización. La crítica de la cultura de masas era en realidad su fijación, pues la identificaba y criticaba, ya fuese en la obra de Stravinsky, ya en el jazz. Adorno vivió la fase naciente de las industrias culturales y las primeras manifestaciones de la subordinación del creador a esta mercantilización. Había motivos para estar alarmado, y cuando observamos fenómenos actuales en la música, sea rock o clásica, no le faltaba razón.

Adorno también cometió errores de interpretación. Es bien conocida su crítica a la radio como instrumento de difusión de la música clásica en el famoso proyecto que llevó con otro sociólogo germanoparlante y exiliado, Karl Lazarsfeld (The Princeton Radio 
Project, 1938-1941). La descontextualización del compositor y el intérprete, la distorsión del sonido... eran algunos de los factores que le llevaron a cuestionar la radio, cuando en realidad este medio ha sido y será siempre un factor de democratización y universalización de la música culta. Además, a medida que ha mejorado la tecnología, cada vez es más posible reproducir un sonido cercano al de las salas de concierto.

Otro de los errores de apreciación de Adorno estuvo en la crítica furibunda hacia el jazz, con una mezcla de elitismo y etnocentrismo. En el año 1936 (publicado en español en 1962) el escrito Sobre el jazz se convirtió acaso en el primer análisis sociológico sobre el nuevo género musical. Lo publica bajo el pseudónimo de Hektor Rottweiler, y realmente se lanza sobre el jazz como un perro de presa. Como ha señalado el historiador marxista Hobsbawn (1999), menos conocido en su faceta de crítico musical de jazz, las observaciones de Adorno sobre este género están entre las mayores estupideces de la historia intelectual de Occidente. No se trató de un exabrupto de juventud, sino de una constante que delataba una incomprensión radical, aún más sorprendente si cabe por tratarse de un intelectual y músico a la vez, que además estaba inmerso en un entorno de vanguardia muy permeable a lo nuevo -la Viena de comienzos del siglo XX- El jazz es despreciado como paradigma de lo que se llamaba en la época música popular o "ligera", la música fundamentalmente de baile producida por la industria cultural para las masas. Pero que guste a las masas para Adorno no significa que sea democrático. Para el filósofo alemán era más bien lo contrario, una forma más sutil de dominación; y dentro de la música popular, el jazz aún era más insidioso para Adorno por consagrar el principio de la improvisación, que solo era emancipador en apariencia pues conduce a "obedecer a la ley manteniéndose diferente. Este comportamiento es el que asume el sujeto que de esta manera, sin darse cuenta, renuncia a los rasgos de reflexión interpretativa y a ser realmente distinto" (citado por Müller-Doom 2003: 299).

A todo lo anterior Adorno unía una interpretación psicoanalítica. En ella, de forma bastante ramplona, sugiere que la síncopa característica del jazz es una forma de orgasmo precoz con origen en la angustia frente a la impotencia. Como ha sugerido Müller-Doom, Adorno se equivocaba desde el principio: "había elegido un título erróneo para su artículo. Pues en realidad Sobre el jazz, del año 36, no analiza el jazz en sí mismo sino su transformación en música bailable y de entretenimiento, aquello en lo que se había convertido en el marco de la popularización del blues y el ragtime. Sin aclararlo explícitamente, Adorno se estaba refiriendo solo al 'hot jazz' o 'jazz' de salón de baile" (Müller-Doom 2003: 299). Quizás el mismo Adorno fuese consciente de la parcialidad de su análisis, dado que en 1933 escribía una Despedida del jazz donde abundaba en la degeneración que había sufrido al alimentar la maquinaria de la industria cultural de masas. Si en un principio pudo ser una forma de expresión auténtica del pueblo negro de los EEUU, y por lo tanto, un vehículo de crítica social, al convertirse en música de baile y entretenimiento pasó a ser una nueva herramienta de dominación. Así, en sus primeros análisis, Adorno al menos todavía distinguía entre el jazz-música y el jazzentretenimiento, entre el jazz-antisistema y el jazz-sistema. 
Sin embargo, lejos de mejorar con el tiempo, la opinión de Adorno sobre el jazz empeoró y se hizo cada vez más dogmática. Lo paradójico es que esta evolución se produce a pesar de sus estancias, primero en el Reino Unido y, después del exilio, en los EEUU, durante la II Guerra Mundial; con lo cual, las críticas genéricas al jazz ya no podían basarse en la ignorancia, en su desconocimiento de las tendencias más vanguardistas del jazz, porque fue testigo de primera mano del nacimiento del bebop.

En términos musicales, después del exilio norteamericano, el filósofo sigue siendo de la opinión de que el jazz es una música demasiado sencilla, directamente simplona, en todos los aspectos: melodía, armonía, forma, etc. Con todo, en "Moda sin tiempo", un texto sobre jazz del año 1953 recopilado posteriormente en el volumen Prismas, lo que más parece molestarle es el ritmo: "un ritmo básico, de tiempos siempre idénticos" (Adorno 1962: 126). Esto convierte al jazz en una música monótona.

A lo anterior habría que sumar que Adorno echa de menos la lógica del funcionamiento de la música clásica: temas, desarrollos, variaciones, etc. "Ninguna pieza de 'jazz' conoce historia; todos sus elementos son por decirlo así desmontables, sin que ningún solo compás se siga de una lógica de desarrollo" (1962: 131). De ahí la paradoja del título: el jazz es lo que llama una moda sin tiempo, en la que paradójicamente el tiempo se congela, porque es siempre igual. "Es el símbolo de una sociedad congelada de antemano, que no dista mucho de la pesadilla de Un mundo feliz de Huxley" (ibíd.). El aspecto en el que según el filósofo se pone más de manifiesto el manierismo del jazz es la improvisación, considerada una impostura musical. "Las llamadas improvisaciones se reducen a paráfrasis más o menos pobres de las fórmulas básicas, bayo cuya máscara se adivina el esquema en cada momento" (1962: 128).

Por otra parte, continúa el crítico, no cabe la improvisación en el jazz porque es producto de la sociedad norteamericana, que está corrompida por la rutina y el consumo de masas. Una sociedad mercantilizada y estandarizada no puede producir jamás una música espontánea. Y, por supuesto, no solo la oferta está estandarizada, sino que las reacciones y el consumo también son estándar. El capitalismo, de esta manera, con el jazz y el consumo musical de las masas ha cumplido el ideal de los regímenes totalitarios: los esclavos felices con su esclavitud. Adorno, por lo tanto, no tiene ningún reparo en comparar el jazz y el nazismo. "El hecho de que precisamente el truco de la síncopa - es decir, el 'jazz' - se hiciera con la dictadura musical sobre las masas advierte de la usurpación, de la existencia de controles totalitarios irracionales en su finalidad última a pesar de toda la racionalidad técnica de sus medios" (1962: 132). En esta desafortunada comparación, no hay diferencias entre los públicos de los distintos países, con lo cual el jazz encarna la pesadilla totalitaria perfecta: "... Todos los entusiastas del 'jazz', en todos los países, tienen en común el momento de la docilidad manifiesto en el paródico frenesí. Por ello recuerda su juego la animal seriedad de los séquitos de los estadios totalitarios...". (1962: 136).

La figura de Adorno como intelectual e incluso como músico es admirable, sin embargo, como hemos dicho, nunca pudo escapar a su sombra de músico de la vanguardia vienesa, tan comprometido con este credo estético que, constantemente, estaba 
polemizando con otras figuras de la música culta europea como Stravinsky o el segundo Schönberg, porque entendía que se habían pasado al bando contrario.

Después de Adorno, como en el resto de la sociología, el panorama sociomusical estuvo dominado por los enfoques conservadores funcionalistas hasta mediados de los sesenta. Destacan los trabajos de Silbermann (1961), que afortunadamente estaba influido también por la sociología empírica de René König (1983) y aplica muy laxamente los supuestos funcionalistas. Todavía en la Alemania de los sesenta, como es sabido, se desarrolló una corriente dentro del funcionalismo que fue la teoría de sistemas de Luhmann (2005). Su ambición teórica le llevó a desarrollos posteriores: la idea de trasplantar la teoría de sistemas autopoiéticos de la biología a la sociología. En esta línea dedicó varios trabajos al mundo del arte, con algunas reflexiones sobre la música.

A menor escala, dentro del marxismo también destaca la figura de (Blaukopf 1988: 71). En su sociología de la música, el sociólogo y musicólogo austríaco combina, en cierto modo, el análisis marxista con el enfoque weberiano del sistema tonal occidental para analizar de qué modo el paso del feudalismo al capitalismo y el nacimiento de la sociedad burguesa condicionaron las transformaciones de la armonía, pero la perspectiva de Blaukopf no es simplista y, sobre todo, no desprecia las fuerzas culturales detrás de los cambios. También hace un análisis comparado del "descubrimiento" del sistema tonal con la "invención" de la perspectiva y la tercera dimensión en la pintura: suponen el paso a la Modernidad. "La representación espacial en la pintura o la polifonía armónica en la pintura son fenómenos que aparecen en la historia del arte casi simultáneamente. La perspectiva y el sistema musical bien temperado, aunque no fuesen descubiertos exactamente al mismo tiempo, constituyen los fundamentos de la modernidad en la pintura y la música" (Blaukopf 1988: 71).

En las artes plásticas la perspectiva pondrá en relación unas líneas con otras. Es lo que produce la ilusión de la perspectiva en el observador. La armonía supone llevar este principio a la música. Para Blaukopf, la música, hasta el descubrimiento del sistema armónico, era bidimensional, carecía de profundidad. La armonía es el principio espacial de la música. Aunque la búsqueda de soluciones en la pintura y en la música empezó en el Renacimiento, en música tardó un poco más, y no se logró hasta bien entrado el Barroco. El proceso de creación del nuevo sistema armónico también está relacionado con la transformación social de la función de la música. La música deja ser un arte subordinado al ritual político y religioso para transitar hacia un arte autónomo; de medio para un fin, a fin en sí mismo. Este proceso empieza en el Barroco y culmina en el Romanticismo. Blaukopf también señala que el descubrimiento estuvo ligado al comienzo de la liberación de la música. "Un fenómeno musical considerado hasta entonces secundario, la armonía, fue observado y conformado conscientemente... la obra musical era una imagen orgánica interiormente cerrada, que portaba en sí misma su propia justificación, y que estaba elaborada, se podría decir, de una sola pieza" (Blaukopf 1988: 67). Esta conformación tridimensional de la música producirá también una ampliación del espacio modulatorio. El piano tenía la gran virtud de reflejar visualmente este nuevo espacio. 
Incluimos en este apartado de análisis macro también los enfoques de inspiración weberiana centrados en las instituciones. En Francia destaca el enfoque de la música como profesión, de Menger (2002), o los estudios de Alfred Willener (1997) sobre las jerarquías de estatus en las orquestas sinfónicas. En España hay que destacar la investigación sobre los compositores españoles de Rodríguez Morató (1996) y los trabajos de Noya, Val y Pérez Colman $(2010,2014)$ dedicado a las aportaciones recientes en sociología de la música en España y a la construcción estética del canon del pop rock español.

En Francia emerge la enorme figura de Pierre Bourdieu (1979) que hemos introducido más arriba, aunque su aportación a la sociología de la música no sea tan importante como la relativa a la sociología de la literatura. Pese a que analizó la creación en el campo literario, con la música se centró en el consumo. Definió tres gustos clasificatorios que se correspondían con la jerarquía de clases: gusto de la libertad, gusto de la voluntad y el de la necesidad. El criterio del gusto cultural y artístico sería un producto de la trayectoria familiar y escolar de los individuos, que mediante sus juicios estéticos clasificarían y se clasificarían simbólicamente. El capital cultural es objeto de lucha entre estas tres clases culturales, superponiéndose a la posesión del capital económico. Aplicando su análisis de las estrategias de distinción, analizó el elitismo de la música culta, donde más se deja ver en sus objetivos críticos, antes que analíticos. Y es que en este campo Bourdieu es incluso más determinista que en otros. El rígido isomorfismo de los campos y la homología estructural de los gustos no permiten el eclecticismo de los gustos musicales. Nick Prior (2011: 122) señala que, a pesar de la poca atención que Bourdieu prestó a la música popular, sus ideas han sido aplicadas en múltiples ocasiones en estudios de este tipo: "... Bourdieu ha fijado la agenda para los estudios postmarxistas sobre las prácticas sociomusicales... sus conceptos de capital cultural, campo y hábitus han sido centrales para la formación de un paradigma crítico en la sociología de la música que demuestre cómo lo social produce, contextualiza o penetra en la música..." .

La aplicación de los trabajos de Bourdieu ha sido muy variada, tanto en estudios cuantitativos (cuestiones de gusto o consumo) como cualitativos (construcciones nacionales de cánones musicales, historias del rock). Es interesante ver una fractura geográfica entre estos estudios: los países anglosajones son quienes han seguido más los planteamientos de La distinción, citándose en pocos casos Las reglas del arte. Esta obra, en cambio, ha sido de gran utilidad en países periféricos (España, Brasil, Argentina, Israel) respecto de las metrópolis del rock (EEUU y Reino Unido) en los que el pop-rock ha tenido que imponerse a otros géneros. En estos países "... el trabajo de Bourdieu es reconocido por impulsar la reescritura de elogiosas narraciones musicales que no incorporaban las cuestiones del poder, la lucha y la exclusión. Su función ha sido la de ayudar a modernizar los estudios de música, proporcionando munición contra las historias localistas..." (Prior 2011: 128). En esa línea es indispensable citar los trabajos del sociólogo israelí Motti Regev (1994; 2002; 2007; 2011), pionero en la aplicación del concepto "campo" al pop-rock, así como en el estudio de la constitución del rock como campo cultural en Argentina e Israel. 
Prior también recoge las principales críticas que se han hecho a las teorías bourdieuanas, destacando los trabajos de Georgina Born (2010) y Antoine Hennion (2001; 2002; 2007). Ambos autores coinciden en utilizar el concepto "mediación" para describir cómo las propiedades de la música están en un continuo estado de ensamblaje, abiertas a la recreación (Prior 2011: 131). Hennion defiende también que el gusto no es algo que esté determinado socialmente, sino que es una actividad, y que su consumo dependerá de muchos factores: de los estados de ánimo, de las mediaciones tecnológicas, de los espacios en los que se consume música. Otro de los problemas que se han señalado, de cariz metodológico, es el de la validez comparativa, puesto que el modelo de Bourdieu se sostiene en Francia, pero no tanto en otros países, como muestra la hipótesis alternativa del omnívoro de Peterson (1996), también corroborada por Ariño (2006) en España. Peterson también, en el lado del consumo, se ha caracterizado por las críticas al modelo de la distinción de Bourdieu. Su hipótesis alternativa del omnívoro cultural plantea que los gustos musicales son más eclécticos, y que, por lo tanto, ha disminuido el peso de la clase social y otros condicionantes del gusto. Quizás lo más atractivo de las ideas de Peterson esté en el campo de la creación, o como prefiere, la "producción" de la música. Fue uno de los protagonistas de la nueva sociología de la cultura norteamericana de los años ochenta, en la que emergió el enfoque de la producción. En palabras del propio Peterson (1996) la perspectiva de la producción de la cultura analiza cómo el contenido de la cultura es influido por los distintos entornos en los que se crea, distribuye, valora y consume. Entre las variables que se manejan están el marco legislativo, la tecnología, las carreras y trayectorias típicas de cada género, el papel del mercado y la estructura de la industria. En un estudio clásico, Peterson (1997) analizó el nacimiento e institucionalización de la música country. Dentro de esta escuela de la "producción de la cultura" también hay que destacar a discípulos como Dowd (2002) y Lena (2004) o el enfoque neoinstitucionalista de DiMaggio (1982) que, por otra parte, fue uno de los líderes intelectuales de este movimiento - de hecho fue anterior al de Peterson-y se desarrolló en el análisis de las primeras instituciones culturales de los EEUU -los museos-, o en el de los factores históricos e institucionales que alumbraron las primeras orquestas norteamericanas.

\section{EL NIVEL MESOSOCIOLÓgICO}

El nivel intermedio entre lo micro y lo macro, es decir, el plano meso de las redes sociales, está recibiendo cada vez más atención. En línea con la tradición alemana, Georg Simmel también dedicó unos cuantos ensayos a la música, siempre a caballo entre la sociología y la etnología, en la potente tradición alemana de la etnología comparativa. Su interés por la configuración de estilos de vida nuevos al consolidarse el tejido urbano ([1903] 2001), por ejemplo, le lleva a preguntarse por la aparente contradicción entre un individualismo nuevo y el establecimiento de una sociedad capitalista y urbana. Su análi- 
sis del canto tirolés ([1883] 2003) sigue siendo fresco e interesante, y capta la necesidad de analizar la interacción sin renunciar al marco de teoría sociológica.

Como en el caso de Simmel, Norbert Elias también tenía una vasta cultura musical. Como en otros muchos campos, las aportaciones de Elias han sido tan fundamentales como desconocidas. El sociólogo alemán cultivó con fruición la sociología de la cultura popular y culta: pensemos en su sociología del deporte o en su teoría del símbolo. Desde luego, la contribución más decisiva son sus apuntes para una sociología de Mozart (2002). Analiza la posición contradictoria del artista, situado entre la sociedad cortesana y la sociedad burguesa. Como en El proceso de civilización, Elias también destaca por su magistral análisis de datos, en este caso con la correspondencia privada de Mozart; pero Elias también es muy aleccionador en otros aspectos. Una vez más, la síntesis de lo micro y lo macro, característica de Elias, reaparece cuando intuye el papel de la competencia entre las cortes barrocas alemanas como factor de creatividad artística, un argumento que será retomado posteriormente por analistas contemporáneos. Las preguntas que se plantea Elias son: ¿por qué la explosión barroca? ¿por qué en Alemania o Italia? Todo apunta a que un factor decisivo fue precisamente la fragmentación política del barroco. Lo apunta Elias y lo desarrollan posteriormente Vaubel y Bernholz (2004: 280) "Es sorprendente que los compositores barrocos más famosos procediesen de dos países que se caracterizaban por el más alto grado de fragmentación y diversidad política: Alemania e Italia". Frente a este escenario, en Inglaterra, Francia o España existían estados y cortes centralizadas.

La explicación puede estar en los beneficios que para la música tiene la competencia política entre los Estados, pero también en la rivalidad entre la Iglesia católica y la Reforma protestante. Como subrayan Vaubel y Bernholz (2004) la competición favoreció la innovación cultural. La música y la ciencia, en este sentido, habrían tenido algo en común, ya que ambas se beneficiaron de la pluralidad religiosa y política que permitía a las élites culturales una movilidad, fuesen músicos o físicos. Esta movilidad obligaba a los Estados a competir por el talento artístico, ofreciendo condiciones laborales e intelectuales que redundaban en una mayor creatividad e innovación científica o cultural. Los compositores y músicos italianos y alemanes del Barroco tenían una movilidad laboral enorme, y en cualquier caso muy superior a la de sus equivalentes franceses o ingleses. Vaubel y Bernholz identifican varias maneras en las que la fragmentación habría propiciado una mayor creatividad. Los mecanismos fueron tanto políticos como económicos. La fragmentación política y religiosa favoreció la creatividad a través de dos vías, que Vaubel y Bernholz identifican con los argumentos de Kant y de Hume, dos pensadores de la época que se percataron de los beneficios culturales de la competencia entre los Estados. Para Kant la competencia era una salvaguarda contra la tiranía y una garantía de libertad ideológica, que era la que acarrearía a la postre una mayor innovación cultural. El nexo entre la competencia política y la creatividad estaría entonces en la libertad política y la diversidad ideológica.

Hume parece apuntar más bien a las mismas relaciones internacionales, a la rivalidad entre los Estados, como factor que lleva a que en estos se intente atraer a los 
artistas o científicos garantizando unas condiciones en las que puedan desempeñar su actividad. Entonces, en términos económicos, à la Hume, la competencia entre Cortes y Estados elevaba el prestigio y los salarios de los músicos, y esta mejora de las condiciones de vida les evitaba subsistir dando conciertos o clases, y redundaba así en una mayor capacidad para componer. Al anterior argumento de Hume, habría que añadir otros también de carácter económico, relacionados con los costes de los servicios. Las Cortes pequeñas tendían a consumir más música que las Cortes grandes. Es la trampa de la ópera, en la que sin embargo incurrían muchas Cortes que imitaban a las grandes de Francia. Y también habría que tener en cuenta que los Estados más pequeños, para sobrevivir, necesariamente tienen que ser más abiertos que la grande Estados centralizados. Este mayor grado de apertura al exterior favorecía la tolerancia y la innovación cultural.

Las teorías de redes y del capital social viven un momento de auge. Aunque la teoría de redes no había producido en realidad una teoría sino más bien una metodología y unas técnicas, cada vez son más los defensores de una sociología relacional (Emirbayer y Lozares 2007) La difusión del concepto "capital social", y sobre todo su salto del mundo académico al político, han supuesto un empuje decisivo para estos planteamientos. Existen estudios de redes sociales en entornos artísticos diversos, como la danza (Muntanyola 2011; en publicación) o la industria cinematográfica (Catan y Ferriani 2008). Los analistas de redes han desarrollado nuevas metodologías y técnicas que empiezan a tener cierta difusión. Algunos de los practicantes de este enfoque han colaborado con el de la producción de la cultura. Tal es el caso de Kadushin (1976), quien fue uno de los primeros en analizar las comunidades de artistas con esta perspectiva, comparando las comunidades estéticas con las intelectuales y científicas. Más recientemente, Hackethor y Jeffri (2003) ha analizado las redes sociales de los músicos de jazz.

De difícil clasificación, por su larga y extensa producción intelectual, es Tia DeNora $(1995 ; 2000 ; 2003)$, sin duda una de las figuras del campo en la actualidad. En sus orígenes emplea un enfoque a caballo entre el marxismo y el análisis weberiano de los estilos de vida de la aristocracia y la burguesía vienesas para desmontar el mito de Beethoven como héroe burgués. DeNora subraya la posición contradictoria del artista. Frente a la escuela vienesa clásica, que ponía el énfasis en la simplicidad ilustrada, Beethoven supuso el retorno de un estilo más complejo, destinado a un público de conneusseurs formado por la aristocracia y la alta burguesía; y es que la dinámica de la vida musical vienesa estaba mucho más controlada por la nobleza que en Londres o París. Y esto será así hasta mediados y finales del siglo XIX. El mito romántico afirmaba que Beethoven era el héroe de la burguesía que pugnaba por librarse de las ataduras del Antiguo Régimen. También se pensaba que el ideal de la música absoluta reflejaba esta lucha social. Sin embargo, paradójicamente, la emancipación de la música instrumental habría tenido lugar en los salones y salas de conciertos cortesanos, y no en los burgueses. Las numerosas investigaciones sobre el patronazgo musical en la Viena de Beethoven poco a poco han ido desmontado el mito de la burguesía. La música seria de Beethoven estuvo auspiciada básicamente por la vieja aristocracia vienesa, que buscaba de esta 
manera diferenciarse de la música burguesa, más popular y menos compleja, destinada a un público con un oído menos formado. "La emergencia durante el siglo XIX del gusto por la música seria se debió casi exclusivamente al patronazgo de la élite aristocrática y claramente no fue un resultado de la llegada de la clase media a la vida musical" (DeNora 1995: 316).

Su música absoluta reflejaba el etos aristocrático y respondía a las estrategias de distinción social de la nobleza, en su afán de descalificar a la burguesía en ascenso. Esta básicamente seguía fiel a la música italiana. DeNora (1995) muestra las diferencias a partir de la programación de los teatros que más frecuentaban. En uno de los de la burguesía, el Theater in der Leopoldstadt, en las afueras de la ciudad, por ejemplo, nunca se llegaron a programar obras de Beethoven. Aparte de obras de Haydn y Cherubini, sobre todo se escuchaba a autores italianos como Cimarosa o Paisiello, además de operetas. De Mozart solo se programaron obras ligeras como arias de ópera. En cambio, en los teatros de la nobleza como el Theater an der Wien, patrocinado por la Sociedad de Nobles Asociados (Gesellschaft der associierten Cavaliere) se escuchaban las obras serias de Mozart, como su Réquiem. Y estos fueron los foros en los que también se estrenan las obras de Beethoven, cuando el gusto por lo italiano empezaba a remitir entre la nobleza y a popularizarse entre la burguesía. Si el mito romántico alimentó la idea de que los burgueses sustituyeron a la aristocracia en el mecenazgo, la hipótesis más plausible es la de que la alta burguesía se incorporó a instituciones culturales aristocráticas buscando la proximidad con las élites nobles. Solo entonces la burguesía ascendente engrosó la aristocracia del gusto que fue el público de la nueva música de Beethoven y la vanguardia de la revolución romántica.

El compositor estaba enormemente disgustado por el éxito de los compositores italianos y en particular con la "música fácil" de Rossini entre sus compatriotas. Esto le hacía coquetear con ofertas de mecenas de otros países como Inglaterra o los EEUU, desde que recibió una invitación de la Handel and Haydn Society de Boston para que escribiera un oratorio. El público aristocrático vienés tuvo que publicar una carta abierta al compositor, Llamamiento de sus admiradores, en la que le piden que no les prive del privilegio de componer y estrenar en Viena: "no defraude durante más tiempo las expectativas públicas. Acreciente el valor de sus obras incomparables dándolas a conocer en persona (en Viena). No querrá que los hijos de su genio sean arrancados de su patria para ser representados primero ante extraños". DeNora (1995: 59) El Llamamiento lo publicaron en febrero de 1824 el Theater Zeitung y el Wiener musikalische Zeitung después de que el conde Lichnowsky recopilase diligentemente las firmas. Quienes suscribieron el documento fueron básicamente miembros de la aristocracia, muchos de ellos antiguos mecenas del compositor, más importantes funcionarios de la máquina burocrática del Imperio, a los que había que unir los artistas ligados a la Corte. Y es que para los aristócratas vieneses este austríaco de adopción que era Beethoven, era el máximo exponente de la música del Imperio. En este análisis sociológico de la figura de Beethoven, DeNora se mueve entre el marxismo y el weberianismo. Cuesta pensar que con el tiempo, sin embargo, DeNora haya evolucionado hacia planteamientos claramente postmodernos, que revisaremos y criticaremos en un apartado posterior. 
Frente a los bandazos de DeNora, el sociólogo británico Simon Frith destaca por su coherencia. Le avala una trayectoria de más de cuarenta años, desde su temprana Sociología del rock (1980), campo en el que fue uno de los pioneros europeos. Como Bourdieu, destaca por el manejo de todo tipo de datos, cuantitativos y cualitativos, combinados con espiritu crítico. Ha analizado como nadie la interacción entre los factores de clase y los culturales, tanto en el campo de la creación como en el del consumo. En Art into Pop (1987) investigó la explosión del rock en el Reino Unido a finales de los sesenta, y sobre todo el cómo y el porqué tendió hacia unos planteamientos más artísticos, hacia una música más compleja, que sería lo que diferenciaría el rock inglés del norteamericano. Frith subrayó el papel del sistema educativo, y en particular la institución de las escuelas de arte, arraigadas en la tradición inglesa y, más concretamente, en las ideas de William Morris y el movimiento arts and crafts. En 1890 el artista ya creó en Birmingham una escuela de arte para joyeros y plateros. La Bauhaus alemana se inspiró también en este modelo.

A principios de los sesenta la Nacional Advisory Council on Art Education racionalizó y homogeneizó el sistema para que tuviera un currículo común, sin que la enseñanza perdiese esa inspiración romántica y contracultural que le habían impreso los pioneros del XIX como Morris. Como subraya Frith, "las escuelas de arte eran el entorno natural para los ideales de la contra-cultura" (1987: 48). Para muchos jóvenes británicos las escuelas se convirtieron en una alternativa a la Universidad o a la formación profesional. Además fomentaban la creatividad en la medida en que, aunque era formación reglada, el formato era menos académico. Se basaba más en la aplicación y el learning by doing. Pudo surgir así una comunidad estética en el sentido más profundo del término, puesto que estos estudiantes, entre los que había también muchos universitarios, entendían lo que hacían no como entretenimiento sino como arte: popular, pero arte. Pink Floyd o David Bowie fueron los típicos productos, que contrastaban con el rock proletario de los Beatles, aunque algunos de ellos también asistieron a clases en las art schools, dado que eran más democráticas que las elitistas universidades británicas

Además de este análisis del sistema educativo y sus efectos sobre la creatividad musical, a Frith le debemos otras muchas ideas y enfoques. La trayectoria del sociólogo británico refleja los cambios que se han producido en el Reino Unido en el análisis de la música popular, desde el marxismo de los sesenta hasta la explosión de los enfoques postmodernos. Frith ha sabido encontrar una vía media, siendo el más culturalista de los marxistas y el más sensato de los postmodernos. En sus comienzos, Frith estuvo muy ligado a la escuela de los Estudios Culturales de Stuart Hall. Esta escuela recogió los análisis posmarxistas de la cultura (Gramsci, Raymond Williams) aplicándolos al estudio de las culturas juveniles. Teóricos como Willis (1977) o Hedbige (2004) subrayaron la originalidad del rock, entendiéndolo como la cultura de resistencia de los jóvenes de clase obrera frente al mundo burgués, remarcando mucho la diferencia entre el rock y la música clásica. Para Willis la música clásica y el rock diferían, en primer lugar, en la organización del tiempo. Mientras la primera sacralizaba la estructura de compases, pulsos y tiempos, para el rock había un flujo continuo de pulsos, "un ritmo básico y primitivo", que subvertía las discontinuidades introducidas por los compases. 
Al cuestionar el rígido lenguaje de los compases y los pulsos por compás, los jóvenes proletarios que creaban y escuchaban el primer rock and roll estaban cuestionando el orden burgués. "Al cuestionar el compás, el rock and roll subvertía el sentido del orden y del tiempo ordenado - si todos los elementos de una pieza son iguales, no importa el orden en el que aparezcan-. El rock se puede empezar o parar en cualquier momento; puede suspenderse en un determinado momento, y retomarse poco después: no necesita un decrescendo para marcar el final" (Willis 1977: 53). Sin duda, el autor exagera para sacralizar la libertad del rock y oponerla a la rigidez de la música clásica. Es evidente que en el rock también hay recursos estéticos que dan forma al discurso, y convenciones aceptadas por los creadores; pero a Willis lo que importaba era marcar las diferencias entre los dos mundos, que no se acababan ahí.

Hedbige, por su parte, analiza la subcultura punk cual ejemplo de cómo los jóvenes construyen a partir de técnicas de bricolaje subculturas de resistencia, frente a los valores culturales hegemónicos. Profundiza también en las cuestiones de clase, utilizando un esquema homológico que posteriormente el mismo Frith (1981), Vila (1996) o Bennet (2001) han criticado. Otro autor que podemos situar en el nivel meso es Small (1999). Su obra más conocida es un ensayo a caballo entre la sociología, la historia y la crítica social. También se sitúa en tierra de nadie, entre el marxismo y la contracultura. Small ha destacado por su énfasis en el análisis de la música como acción y práctica social: el "musicar", como prefiere decir él, en lugar de música. Desde esta postura se ha destacado por las críticas a la institucionalización de la música culta occidental.

\section{ENFOQUES MICRO}

El fenomenólogo Alfred Schütz (1964) comenzó su ensayo sobre la ejecución musical conjunta con una crítica al logocentrismo del francés. Como en el caso de Weber, la música no era algo periférico a las preocupaciones de Schütz y tiene varios ensayos en sus Collected Papers, como el del análisis de la figura de Mozart. De hecho, toma la música como ejemplo de relación social no mediada lingüísticamente, al igual que las relaciones sexuales. Lo que subraya Schütz precisamente es la posibilidad de una sintonía mutua entre los músicos sin necesidad de comunicación lingüística.

¿Cómo se logra tocar juntos? Schütz subraya la importancia del tiempo compartido por compositor, ejecutantes y oyentes, pero también introduce el espacio. De esta forma Schütz inaugura y se anticipa a los estudios actuales sobre la actividad musical desde una sociología del cuerpo y de la interacción. Existen muchos estudios sobre fenomenología del cuerpo y embodied cognition basados en estudios etnográficos, pero con una base teórica. Podemos citar aquí las publicaciones recientes de la misma DeNora (2003), que parece abarcar mucho con poca solidez empírica; el estudio sobre música, emociones y danza de Muntanyola y Belli (en prensa) y la revisión bibliográfica sobre música y conocimiento corpóreo que propone Pelinski en la revista Trans (2005). También el interaccionismo simbólico ha operado en el campo musical y es una corriente 
muy activa en la actualidad, como demuestran los trabajos de Berliner (1994), Malholtra (1981) o Weeks (1996) sobre distintos géneros musicales, de la música clásica al jazz.

El antecedente de estos trabajos está en la exploración del mundo del arte a partir de los trabajos pioneros de Howard Becker (2008). Como buen interaccionista, Becker empieza a construir su teoría de los mundos y la institucionalización desde abajo, a partir de la interacción mutua entre artistas, críticos, etc., para llegar finalmente al plano macro de los mundos del arte. A esta institucionalización se llega a través de los procesos que son la lingua franca del interaccionismo: etiquetamiento, definición de la situación, vocabularios de motivos, etc. Estos procesos culminan con la emergencia de mundos del arte como subculturas institucionalizadas y autónomas. La literatura, el arte o la música tienen sus propias reglas y procesos específicos. También hay procesos y mecanismos comunes. Es famosa su clasificación de 4 tipos de artistas: profesionales integrados, disidentes, folk o populares y naif. Se ha criticado de Becker su poca sensibilidad hacia los factores políticos y a las cuestiones de poder. Las instituciones y el Estado emergen como un actor más en la interacción sin más capacidad de influencia. No se considera entonces el poder estructurador de la política y el Estado en el mundo del arte, algo a lo que Bourdieu prestaba tanta atención.

Sin embargo, se olvida con frecuencia que Becker básicamente analiza el mundo norteamericano del arte que, como es sabido, está más liberalizado que el estatista mundo europeo, en el que las subvenciones públicas son clave. Algunos han tachado a Becker de etnocéntrico por basar su teoría en los EEUU. A estos defensores de Bourdieu en detrimento de Becker solo se les puede recordar que Bourdieu era tanto o más sesgado y etnocéntrico que Becker, puesto que el francés básicamente pensaba en Francia. El mismo Becker fue músico de jazz antes que sociólogo, de forma que el género fue uno de los primeros campos en los que empleó su teoría de los mundos del arte. Paul Lopes (2002) aplica ideas de Becker pero también de Peterson al análisis del jazz, y en particular al nacimiento del bebop como cristalización del campo del jazz como arte, y no como simple entretenimiento. Recientemente, Becker se ha interesado por las pautas de improvisación en el mismo mundo del jazz (Faulkner y Becker, 2009).

Sin duda, una de las contribuciones más originales dentro de esta línea de análisis ha sido la de Eyerman y Jameson (1997) sobre el papel que juega la música en la movilización y la acción colectiva. Desde las teorías de los marcos de sentido en la acción colectiva, analizan cómo se resuelven los movimientos sociales a través de las emociones que solo puede producir la música. Finalmente, existen aportaciones interesantes des de la sociología de la música francesa des de la perspectiva histórica (Ravet, 2010) y de género (Buscatto, 2003) cuya tesis fue dirigida por Howard Becker

\section{Conclusiones}

En este trabajo hemos tratado de hacer una síntesis de los enfoques teóricos de la sociología de la música, desde los clásicos hasta la actualidad, algo difícil, y aún más en tan pocas páginas. Para completar la clasificación teórica de estas propuestas micro, 
meso y macrosociológicas hemos intentado tomar, siempre que hemos podido, algunos ejemplos de la investigación empírica o el análisis crítico para ilustrarlas. Ofrecemos una recapitulación de las propuestas de clásicos como Weber, Adorno, DeNora y Bourdieu, e incluimos las nuevas propuestas metodológicas desde el análisis de redes sociales, la etnografía y los estudios culturales.

Para consolidar un marco teórico de referencia debemos huir de la trampa postmoderna, la renuncia a la crítica sociológica, y reconocer el carácter necesario de una verdadera teoría social. En la actualidad podemos decir que la sociología de la música se mueve entre dos grandes líneas de investigación dominantes: por un lado, la sociología neoinstitucionalista anglosajona, sin duda potente en el terreno empírico, pero más pobre desde el punto de vista teórico; por otro lado, con figuras que han girado hacia el postmodernismo, como DeNora. Ahora bien, la sociología cultural postmoderna apenas es ya sociología, pero tampoco es musicología, puesto que la música suele ser solo una excusa para aplicar argumentos que en realidad tienen su origen en lo visual o lo tecnológico. El postmodernismo acaba, a la postre, en una musicología sin música y una sociología sin sociedad.

La sociología de la música debe encontrar su camino entre Escila y Caribdis. Para esta "nueva sociología de la música" deberemos integrar los tres planos: macro, meso y micro; y deberemos analizar los procesos de creación, intermediación y recepción. Por poner un ejemplo, suponiendo que solo tuviésemos tres géneros musicales (clásica, jazz y rock), el marco de análisis seguiría la Tabla 1 que proponemos al inicio de este artículo, y la mayor parte de las casillas siguen vacías.

En el lado crítico desde luego también podemos introducir la dimensión moderno/ postmoderno para compatibilizar el análisis de los factores materiales e institucionales con el de los culturales y simbólicos. El postmodernismo nos ha recordado la importancia de la cultura, pero no todo es cultura, identidades y símbolos. Nos hemos pasado de un materialismo ramplón a un culturalismo igual de ramplón. Hay que volver a hacer sociología, o de lo contrario, estaremos olvidando la aportación de clásicos como Weber, Simmel, Schütz o Elias.

Desde una perspectiva metodológica, autores ya citados como Nick Prior (2010), Georgina Born (2010) o Antoinne Hennion (2002) han planteado que la sociología de la música, y de la cultura en general, ha dejado de lado el propio objeto artístico en su análisis. Para evitar una sociología reduccionista es necesario reintroducir las cuestiones estéticas en el análisis sociológico, como ya hicieran Adorno o Weber. Lejos de la reificación o de la mistificación, la música puede ser analizada como práctica social dentro de una perspectiva histórica e intersubjectiva.

\section{RefERENCIAS BibLIOGRÁFICAS}

Adorno, T. W. 1962. "Moda sin tiempo. Sobre el jazz". Pp.126-141 en Prismas. La crítica de la cultura y la sociedad. Barcelona: Ariel. 
Adorno, T. W. 2000. Sobre la música. Barcelona: Paidós.

Adorno, T. W. 2009. "Disonancias. Introducción a la sociología de la música". Obra completa, vol. XIV, editado por Rolf Tiedemann. Madrid: Akal.

Ariño, A. 2006. La participación cultural en España. Madrid: Fundación Autor.

Becker, Howard S. 2008. Los mundos del arte. Sociología del trabajo artístico. Buenos Aires: Universidad Nacional de Quilmes.

Benjamin, W. [1936] 1973. La obra de arte en la época de su reproductibilidad técnica. Madrid: Taurus.

Bennet, A. 2001. Cultures of Popular Music. Chicago: Open University.

Berliner, P. F. 1994. Thinking in Jazz. The Infinite Art of Improvisation. Chicago: Chicago University Press.

Blaukopf, K. 1988. Sociología de la música. Madrid : Real Musical.

Born, G. 2010. "The social and the aesthetic: for a post-Bourdeuian theory of cultural production". Cultural Sociology 4: 171-208.

Bourdieu. P. 1979. La distinction. París: Seuil.

Bourdieu, P. 1994. Las reglas del arte. Barcelona: Anagrama.

Buscatto M. 2003. "Chanteuse de jazz n'est point métier d'homme. L'accord imparfait entre voix et instrument en France". Revue française de sociologie 44 (1): 33-60.

Cattani, G. and Simone Ferriani. 2008. "A Core/Periphery Perspective on Individual Creative Performance: Social Networks and Cinematic Achievements in the Hollywood Film Industry". Organization Science 9: 824-844.

DeNora, T. 1995. Beethoven and the Construction of a Genius. Berkeley: University of California Press.

DeNora, T. 2000. Music in Everyday Life. Cambridge: Cambridge University Press.

DeNora, T. 2003. After Adorno: Rethinking Music Sociology. Cambridge: Cambridge University Press.

Dimaggio, J. 1982. "Cultural entrepreneurship in $19^{\text {th }}$ century Boston". Media, Culture and Society 4: 35-50.

Doane, R. 2006. "The habitus of dancing. Notes on the swing dance revival in NY". Journal of Contemporary Ethnography 35: 84-116.

Dowd, T. et al. 2002. "Organizing the musical canon: the repertoires of major US symphonic orchestras, 1842-1969". Poetics 30: 35-61.

Eagleton, T. 2000. The Idea of Culture. Oxford: Blackwell.

Elias, N. 2002. Mozart: sociología de un genio. Barcelona: Península.

Eyerman, R. y A. Jameson. 1997. Music and Social Movements. Cambridge: Cambridge University Press.

Faulkner, R. y Becker, H. 2009. Do You Know...? The Jazz Repertoire In Action. Chicago: University of Chicago Press.

Fontcuberta, D. 2003. "La fotografía como discurso pseudodocumental". Curso de posgrado Espejos Rotos. Barcelona: Museu d'Art Contemporani de Barcelona, MACBA. 
Frith, S. 1980. Sociología del rock. Madrid: Júcar.

Frith, S. 1981. Sound Effects: Youth, Leisure and the politics of rock. New Cork: Pantheon Books.

Frith, S. 1987. Art into pop. Londres: Methuen young books.

Heckathorn, D. y Jeffri J. 2003. "Social Networks of Jazz Musicians," editado por Douglas D. Heckathorn and Joan Jeffri, pp. 48-61 en Changing the Beat: A Study of the Worklife of Jazz Musicians, Volume III: Respondent-Driven Sampling: Survey Results by the Research Center for Arts and Culture, National Endowment for the Arts Research Division Report \#43, Washington DC.

Hedbige, D. 2004. Subcultura. El significado del estilo. Barcelona: Paidós.

Hennion, A. 2001. "Music lover: taste as performance". Theory, Culture \& Society 18: 1-22.

Hennion, A. 2002. La pasión musical. Barcelona: Paidós.

Hennion, A. 2007. "Those things that hold us together: taste and sociology". Cultural Sociology 1: 97-114.

Hobsbawm, E. 1999. Gente poco corriente: resistencia, rebelión y jazz. Barcelona: Crítica.

Hormigos, J. 2008. Música y sociedad. Análisis sociológico de la cultura musical de la posmodernidad. Madrid: Fundación Autor.

Kadushin, C. 1976. "Networks and circles in the production of culture". Pp. 107-122 en The Production of Culture, editado por R. Peterson. Beverly Hills: Sage.

König, R. 1983. Los artistas y la sociedad. Barcelona: Alfa.

Latour, B. 2005. Rassembling the Social: An Introduction to Acto-network Theory. Oxford: Oxford University Press.

Lena, J. 2004. "Sonic Networks: economic, stylistic and expressive dimensions of rap music". Poetics 32: 297-310.

Lopes, P. 2002. The Rise of a Jazz Art World. Cambridge: Cambridge University Press.

Lozares, C. 2007. Interacción, redes sociales y ciencias cognitivas. Granada: Comares.

Luhmann, N. 2005. El arte de la sociedad. Herder: Barcelona.

Malholtra, V. A. 1981. "The social accomplishment of music in a symphony orchestra: a phenomenological analysis". Qualitative Sociology 4: 102-125.

McLuhan, M. \& Quentin Fiore with J. Angel (coord.). 1967. The Medium is the Massage: An Inventory of Effects. Nueva York: Random House.

Menger, P. M. 2002. Le paradox du musician. Le compositeur, le mélomane et l"État dans la societé contemporaine. París: Hartmann.

Middleton, R. 1990. Studying Popular Music. Philadelphia: Open University Press.

Müller-Doohm, S. 2003. En Tierra de Nadie. Th. W. Adorno, una biografia Intelectual. Barcelona: Herder.

Muntanyola, D. 2010. Danza y cognición: el proceso de creación coreográfica, Pp. 99-114 en Noya, J., F. Del Val y M. Perez (Ed.) 2010. Musyca: Musica, sociedad y creatividad artística. Madrid: Biblioteca Nueva. 
Muntanyola, D. 2014. "Cognitive Account of Expertise: Why Rational Choice Theory is (often) a Fiction." Theory \& Psychology. DOI 10.1177/0959354313513510.

Muntanyola, D. y Belli, S. 2013. "Bodies, music and emotions: An ethnography of a dance company." Pp. 563-580 en Actas del Il Congreso sobre Metodología de la Investigación en Comunicación. Segovia: Universidad de Segovia.

Noya, J., F. Del Val y M. Perez (Ed.) 2010. Musyca: Musica, sociedad y creatividad artística. Madrid: Biblioteca Nueva.

Pelinski, R. 2005. "Corporeidad y experiencia musical". Trans. Revista transcuntural de música 9 (artículo 13). www.sibetrans.com/trans/a177/corporeidad-y-experiencia-musical.

Peterson, R. 1996. "Changing hibrow taste: From snob to omnivore". American Sociological Review 61: 900-907.

Peterson, R. 1997. Creating Country Music. Fabricating Authenticity. Chicago: Chicago University Press.

Pinch, T. 1992. Analog Days. The Invention and Impact of Moog Synthetizer. Harvard: Harvard University Press.

Prior, N. 2011. "Critique and renewal in the sociology of music: Bourdieu and beyond". Cultural sociology 5: $121-138$.

Ramsey, C. 2004. Race Music. Black Cultures from Bebop to Hip-hop. Berkeley: University of California Press.

Ravet, H. 2010. "Sociologies de la musique". L'année sociologique 2 (60): 271-303.

Regev, M. 1994. "Producing Artistic Value: The Case of Rock Music". The Sociological Quarterly 35: 85-102.

Regev, M. 2002. "The "Pop-Rockization" of Popular Music". Pp. 251-264 en Studies in Popular Music, editado por Dave Hesmondhalgh and Keith Negus. London: Arnold/New York: Oxford University Press.

Regev, M. 2007. "Ethno-National Pop-Rock Music: Aesthetic Cosmopolitanism Made from Within". Cultural Sociology 1: 317-341.

Regev, M. 2011. "Pop-Rock Music as Expressive Isomorphism: Blurring the National, the Exotic, and the Cosmopolitanism in Popular Music". American Behavioral Scientist 20: 1-16.

Rodríguez Morató, A. 1996. Los compositores españoles. Un análisis sociológico. Madrid: CIS/SGAE.

Shepherd, J. 1991. Music as Social Text. Oxford: Polity Press.

Shepherd, J. y P. Wicke. 1997. Music and Cultural Theory. Cambridge: Polity Press.

Schütz, A. 1971. "Making music together. A study in social relationship." Pp. 169-178 en Collected papers. II, Studies in social theory. The Hague: Martinus Nijhoff.

Silbermann, A. 1961. Estructura social de la música. Madríd: Taurus.

Simmel, G. [1882] 2003. Estudios psicológicos y etnológicos sobre música. Buenos Aires: Gorla.

Simmel, G. [1903] 2001. El Individuo y la libertad: ensayos de crítica de la cultura. Barcelona: Península.

Small, C. 1999. Música, sociedad, educación. Alianza: Madrid.

Sontag, S. 1973. On Photography. Nueva York: Picador. 
Val, F. del; Noya, J. y Pérez-Colman, C. M. 2014. "¿Autonomía, sumisión o hibridación sonora? La construcción del canon estético del pop-rock español". Revista Española de Investigaciones Sociológicas, 145: 147-180.

Vaubel, R. y P. Bernholz. 2004. Political Competition, Innovation, and Growth in the History of Asian Civilizations. Cheltenham, UK-Northampton, MA: Edward Elgar.

Vila, P. 1996. "Identidades narrativas y música. Una primera propuesta para entender sus relaciones". Trans. Revista transcuntural de música 2 (artículo 14).

Weber, M. 1911. "Fundamentos racionales y sociológicos de la música". Pp. 1.118-1.183 en Economía y Sociedad. México-Madrid: FCE.

Weeks, P. 1996. "A Rehearsal of a Beethoven Passage: An Analysis of Correction Talk". Research on Language and Social Interaction 29 (3): 247-290.

Willener, A. 1997. La pyramide symphonique. Exécuter, créer? Une sociologie des instrumentistas d"orchestre. Zurich: Seismo.

Williams, R. 1982. The Sociology of Culture. Nueva York: Schocken.

Willis, P. 1977. Learning to Labour. Londres: Ashgate.

Zolberg, V. 2002. Sociología de las artes. Madrid: SGAE.

JAVIER NoYA es Profesor Titular de Sociología en la Universidad Complutense de Madrid, en el departamento de Sociología V. Director del grupo de investigación MUSYCA (Música, Sociedad y Creatividad Artística), pionero en España en el estudio de la música desde una perspectiva sociológica. $\mathrm{Ha}$ coordinado el libro Música, Sociedad y Creatividad (Biblioteca Nueva, 2010). Investigador Principal del Real Instituto Elcano para el Área de Imagen Exterior de España y responsable del Barómetro Elcano desde su creación. Es autor de varios libros e informes sobre la imagen internacional de España y recientemente ha publicado los libros Teorías sociológicas de la globalización (Tecnos, 2010) e Internacionalización, crecimiento, redistribución. Los españoles ante la globalización (Tecnos, 2010).

Fernán del VAL es Licenciado en Sociología por la Universidad Complutense de Madrid. Profesor-tutor de Sociología en la UNED. Forma parte del grupo de investigación MUSYCA (Música, Sociedad y Creatividad Artística) y es secretario de la SIBE (Sociedad de Etnomusicología) y tesorero de la rama española de la IASPM (International Association for the Study of Popular Music).

Dafne Muntanyola es Doctora en sociología por la Universidad Autónoma de Barcelona (2008), estudia el conocimiento distribuido y corpóreo en el estudio de entornos de trabajo expertos (Muntanyola, 2014), con especial énfasis en la metodología audiovisual (Muntanyola, 2013). Ha sido investigadora postdoctoral en la Université de Nice, en el departamento de ciencia cognitiva de la University de California, San Diego (UCSD) y en la Universidad Autónoma de Madrid, con becas Caja Madrid, Fulbright/MEC y Alianza. Ha coordinado el trabajo de campo etnográfico de una compañía de danza inglesa y de un equipo de gestión de emergencias médico.

RECIBIDO: 23/03/2013

ACEPTADO: $18 / 09 / 2013$

PUBLICADO ONLINE: 25/06/2014 